\title{
Splicing factor hnRNP A2 activates the Ras-MAPK-ERK pathway by controlling A-Raf splicing in hepatocellular carcinoma development
}

\author{
ASAF SHILO, ${ }^{1}$ VERED BEN HUR, ${ }^{1}$ POLINA DENICHENKO, ${ }^{1}$ ILAN STEIN, ${ }^{2,3}$ ELI PIKARSKY, ${ }^{2,3}$ JENS RAUCH, ${ }^{4}$ \\ WALTER KOLCH, ${ }^{4}$ LARS ZENDER, ${ }^{5}$ and ROTEM KARNI ${ }^{1,6}$ \\ ${ }^{1}$ Department of Biochemistry and Molecular Biology, Institute for Medical Research Israel-Canada (IMRIC), Hebrew University-Hadassah \\ Medical School, Jerusalem 91120, Israel \\ ${ }^{2}$ Department of Immunology and Cancer Research, Institute for Medical Research Israel-Canada (IMRIC), Hebrew University-Hadassah Medical \\ School, Jerusalem 91120, Israel \\ ${ }^{3}$ Department of Pathology, Hebrew University-Hadassah Medical Center, Jerusalem 91120, Israel \\ ${ }^{4}$ Systems Biology Ireland, University College Dublin, Belfield, Dublin 4, Ireland \\ ${ }^{5}$ Division of Molecular Oncology of Solid Tumors, Department of Internal Medicine I, University Hospital Tuebingen, 72076 Tuebingen, Germany
}

\begin{abstract}
In recent years, it has become clear that splicing factors play a direct role in cancer development. We showed previously that splicing factors SRSF1, SRSF6, and hnRNP A2/B1 are up-regulated in several cancers and can act as oncogenes when up-regulated. Here we examined the role of splicing factors hnRNP A1/A1b and hnRNP A2/B1 in hepatocellular carcinoma (HCC). We show that the splicing factors hnRNP A1 and hnRNP A2 are up-regulated in HCC tumors derived from inflammation-induced liver cancer mouse model. Overexpression of hnRNP A1 or hnRNP A2, but not the splicing isoform hnRNP B1, induced tumor formation of immortalized liver progenitor cells, while knockdown of these proteins inhibited anchorage-independent growth and tumor growth of human liver cancer cell lines. In addition, we found that cells overexpressing hnRNP A2 showed constitutive activation of the Ras-MAPK-ERK pathway. In contrast, knockdown of hnRNP A2 inhibited the Ras-MAPK-ERK pathway and prevented ERK1/2 activation by EGF. Moreover, we found that hnRNP A2 regulates the splicing of $A-$ Raf, reducing the production of a short dominant-negative isoform of A-Raf and elevating the full-length A-Raf transcript. Taken together, our data suggest that hnRNP A2 up-regulation in HCC induces an alternative splicing switch that down-regulates a dominant-negative isoform of A-Raf, leading to activation of the Raf-MEK-ERK pathway and cellular transformation.
\end{abstract}

Keywords: alternative splicing; hnRNP A2/B1; RNA processing; A-Raf; MAPK; liver cancer

\section{INTRODUCTION}

The process of alternative splicing is widely misregulated in cancer, and many tumors express new splicing isoforms that are either absent or expressed at low levels in the corresponding normal tissue (Roy et al. 2005; Xi et al. 2008; Venables et al. 2009; David and Manley 2010). Many oncogenes and tumor suppressors are differentially spliced in cancer cells, and it has been shown that many of these cancer-specific isoforms contribute to the transformed phenotype of cancer cells (Venables 2004; Srebrow and Kornblihtt 2006; Kim et al. 2008). Moreover, mutations in several components of the spliceosome were recently discovered in several cancers and are predicted to be driver mutations, providing further confirmation that splicing factors are indeed important players in can-

\footnotetext{
${ }^{6}$ Corresponding author

E-mail rotemka@ekmd.huji.ac.il

Article published online ahead of print. Article and publication date are at http://www.rnajournal.org/cgi/doi/10.1261/rna.042259.113.
}

cer development (Papaemmanuil et al. 2011; Quesada et al. 2012). However, there is only limited information regarding the causal/functional role of alternative splicing regulators in cancer development and progression (Karni et al. 2007; Jia et al. 2010; Golan-Gerstl et al. 2011; Lefave et al. 2011; Anczukow et al. 2012; Cohen-Eliav et al. 2013).

hnRNP proteins are abundant RNA-binding proteins expressed in most human tissues (Hanamura et al. 1998; Cooper et al. 2009). The hnRNP A/B family is a subset of hnRNP proteins with closely related sequences and a conserved modular structure (Dreyfuss et al. 2002; He and Smith 2009). The structure of the hnRNP A/B proteins is composed of two major domains: two RNA-recognition motifs (RRMs) that bind specific RNA sequences, and a glycine-

(C) 2014 Shilo et al. This article is distributed exclusively by the RNA Society for the first 12 months after the full-issue publication date (see http:// rnajournal.cshlp.org/site/misc/terms.xhtml). After 12 months, it is available under a Creative Commons License (Attribution-NonCommercial 3.0 Unported), as described at http://creativecommons.org/licenses/by-nc/3.0/. 
rich domain (G domain) (He and Smith 2009). HNRNP A1 encodes for hnRNP A1 and its splicing variant hnRNP Alb, which contains an additional 52 amino acids in the C-terminal glycine-rich region (Buvoli et al. 1990; Blanchette and Chabot 1997; He and Smith 2009). HNRNP A2/B1 encodes for hnRNP A2 and its splicing variant hnRNP B1, which contains an additional 12 amino acids near the $\mathrm{N}$ terminus (Burd et al. 1989; He and Smith 2009). An unsolved question is the biochemical and biological differences between hnRNP A/B protein family members and their splicing isoforms. To date, their splicing activities, both in vitro and in knockdown or transient transfection assays, showed similar effects on several substrates (Burd et al. 1989; Dreyfuss et al. 2002; Patry et al. 2003). Thus, it is not clear to what extent there is redundancy in their splicing targets and biological or oncogenic activities. Previous studies found overexpression of hnRNP Al and hnRNP A2/B1 in lung and breast cancers (Fielding et al. 1999; Zhou et al. 2001b). Knockdown of hnRNP A1 and A2/ B1 in breast cancer cells induced apoptosis that was specific for cancer cells (Patry et al. 2003). We reported recently the first direct evidence that hnRNP A2/B1 plays an important role as a driver oncogene in glioblastoma development (Golan-Gerstl et al. 2011). Recent studies found that hnRNP A1 and hnRNP A2/B1 modulate alternative splicing of the glycolytic PKM2 enzyme in cancer cells, suggesting a possible role for hnRNP A1 and hnRNP A2/B1 in the regulation of tumor metabolism (Clower et al. 2010; David et al. 2010).

Hepatocellular carcinoma (HCC) is the most common primary hepatic malignancy and the third most common cause of cancer-related death worldwide. Incidence remains highest and is steadily increasing across the developed world (Shiraha et al. 2013). The connection between chronic inflammation and liver carcinogenesis is well established (Pikarsky et al. 2004; Finkin and Pikarsky 2011; He and Karin 2011). A recent study showed that in HCC, hnRNP A1 overexpression enhances invasiveness (Zhou et al. 2013). Other splicing factors such as SRSF1 have also been shown to regulate alternative splicing of important HCC tumor suppressors and oncogenes (Munoz et al. 2012). Here we investigated the expression and roles of hnRNP A1, hnRNP A2, and their corresponding isoforms, hnRNP Alb and hnRNP B1, respectively, in HCC development. We found that hnRNP A1 and A2 are up-regulated in a mouse model of inflammation-induced HCC (Pikarsky et al. 2004). Moreover, transduction of immortal progenitor hepatocytes with hnRNP A1 or A2, but not its isoform $\mathrm{B} 1$, induced tumorigenesis, while hnRNP A1 or A2 knockdown in human HCC cells inhibited their transformation and tumorigenesis, indicating that hnRNP A1 and $\mathrm{A} 2$ are putative oncogenes in HCC development. Furthermore, we found that hnRNP A2 up-regulation caused constitutive activation of the RAS-Raf-MAPK-ERK pathway through regulation of A-Raf alternative splicing. Finally, activation of the RAS-Raf-MAPK-ERK pathway by hnRNP A2 renders HCC cells resistant to a MEK1 pharmacological inhibitor, suggesting that hnRNP A2 up-regulation might serve as a drug-resistance mechanism.

\section{RESULTS}

\section{hnRNP A1/A1b and hnRNP A2/B1 proteins are up-regulated in inflammation-induced mouse HCCs}

To examine if hnRNP A1/A1b or hnRNP A2/B1 plays a role in liver cancer development, we compared normal and tumor liver tissue samples from an inflammation-induced liver cancer $M d r 2^{-l-}$ mouse model. The mouse $M d r 2$ gene encodes for the Abc4 protein. Knockout of this gene leads to chronic hepatic inflammatory disease (Pikarsky et al. 2004). When the mice are 6 to 9 mo of age, preneoplastic lesions develop in the liver, eventually progressing to metastatic liver cancer in the terminal phase. During progression into malignant lesions, $M d r 2^{-/-}$tumor cells accumulate mutations and other genetic abrogations and are thus genetically variable. The $M d r 2^{-/-}$mice therefore provide a tumor progression model of value for the study of hepatic carcinogenesis (Pikarsky et al. 2004). We found higher levels of hnRNP A1 mRNA and protein in most liver tumor samples and found higher levels of hnRNP A 2 mRNA and protein in a large portion of liver tumors compared with normal mouse liver tissue from the $M d r 2^{-/-}$mice (Fig. 1A-E). hnRNP B1 and hnRNP Alb were hardly detected in these samples. mRNA levels of hnRNP $\mathrm{H}$, a close family member of the hnRNP $\mathrm{A} / \mathrm{B}$ proteins, were elevated in some tumors (Supplemental Fig. S1A). Interestingly, most of the tumors that overexpress hnRNP H did not overexpress hnRNP A1 or A2/B1 (Supplemental Fig. S1B-D).

\section{hnRNP A1/A1b and A2, but not hnRNP B1, transform progenitor liver cells}

In order to examine the oncogenic activity of the different hnRNP A1/A2 isoforms, we expressed different hnRNP A/B isoforms in $\mathrm{TP}^{-1-}$ mouse embryonic progenitor hepatocytes overexpressing c-myc (PHM-1 cells) (Fig. 2A,B; Zender et al. 2006; Shimoni-Sebag et al. 2013). We then examined the growth rate of cells expressing the different isoforms. We found that while hnRNP A1 had a small proliferative effect, none of the other hnRNP A1/A2 isoforms changed significantly the proliferation rate of the cells (Fig. 2C). We injected nude/nude mice subcutaneously with pools of PHM-1 cells transduced with the different hnRNP A1/A2 isoforms. Mice injected with PHM-1 cells expressing either hnRNP A1 or hnRNP A2, and to a lesser degree hnRNP Alb, formed tumors, whereas mice injected with PHM-1 cells expressing hnRNP B1 did not form tumors (Fig. 2D,E).

\section{hnRNP A2/B1 and hnRNP A1/A1b are required for HCC tumor maintenance}

To better understand the involvement of the different isoforms in liver cancer and to examine if hnRNP A1/A1b or $\mathrm{hnRNP} A 2 / \mathrm{B} 1$ is required for maintenance of the transformed 

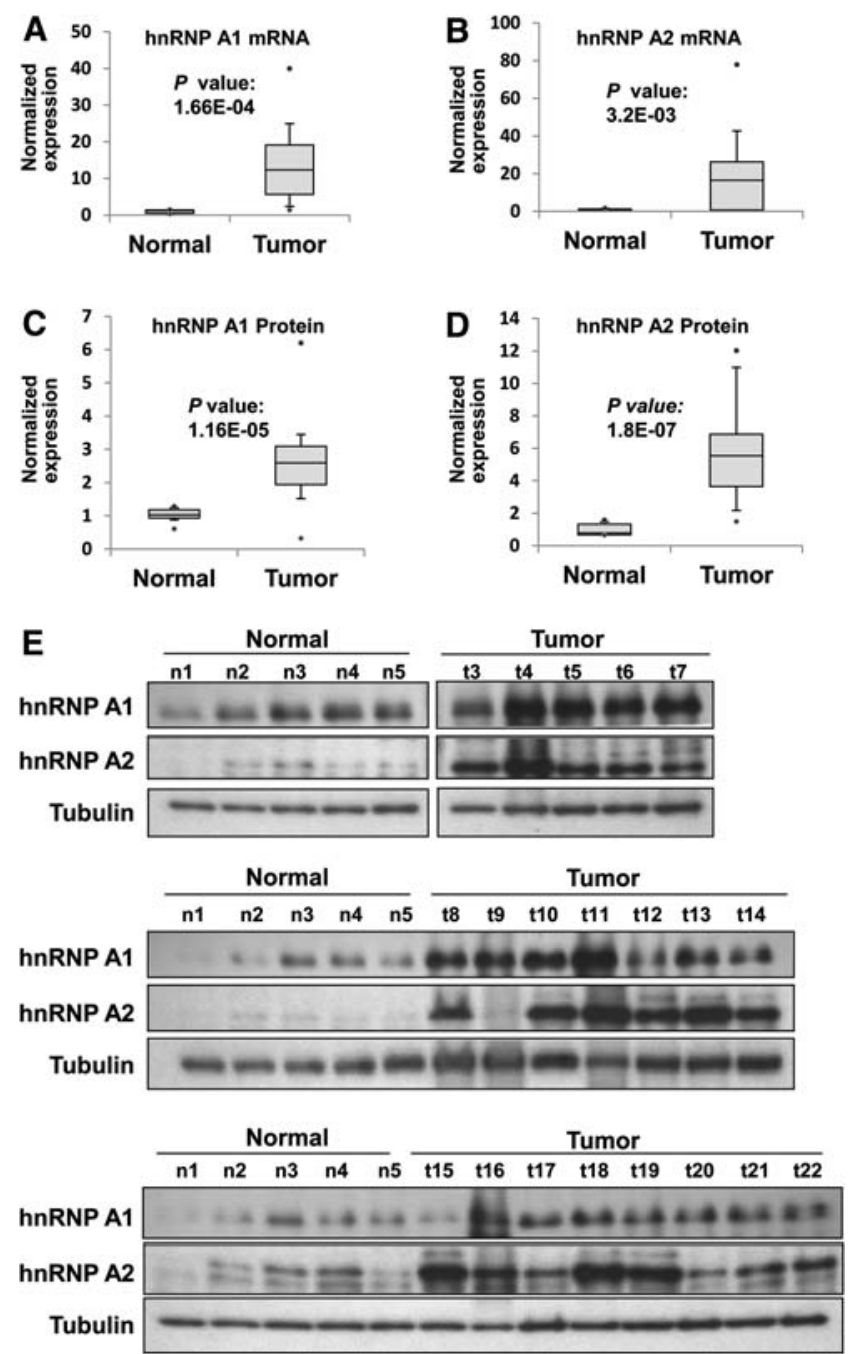

FIGURE 1. Elevated hnRNP A2 and hnRNP A1 expression in mouse liver tumors. $(A, B)$ Box plot representation of qRT-PCR analysis of hnRNP A1 (A) and hnRNP A2 (B) RNA levels in $M d r 2^{-1-}$ mouse liver tumors $(n=22)$ and normal mouse liver tissue $(n=5)$. All samples were normalized to GAPDH mRNA levels, and the average expression in normal liver tissue was arbitrarily set at one. Medians are represented by solid black lines. Top and bottom box edges represent the third and first quartile. Whiskers indicate 90 and 10 percentile; asterisks, minimum and maximum points. $(C, D)$ Box plot representation of protein levels for hnRNP A1 (C) and hnRNP A2 (D) in $M d r 2^{-/-}$mouse liver tumors and normal liver tissue. All samples were normalized to tubulin protein levels and to the average expression in normal liver tissue, which was arbitrarily set at one. Medians are represented by solid black lines. Top and bottom box edges represent the third and first quartile. Whiskers indicate 90 and 10 percentile; asterisks, minimum and maximum points. (E) Western blot analysis of hnRNP A1 and hnRNP A2 protein levels in $M d r 2^{-l-}$ liver tumors ( $\mathrm{t}$ ) and normal (n) mouse liver tissue. Tubulin was used as loading control. Numbers indicate sample number.

phenotype, we knocked down either hnRNP A2/B1 or hnRNP A1/A1b expression in the human HCC cell line HuH7 (Fig. $3 \mathrm{~A})$. We found that cells knocked down for either hnRNP A1/A1b or hnRNP A2/B1 expression showed a reduced ability to form colonies in soft agar (Fig. 3B,C). Reduced anchorage-independent growth in soft agar can be the result of a combination of reduced invasion, sensitivity to apoptosis, and reduced proliferation. Detachment of most epithelial cells from the extracellular matrix induces programmed cell death called anoikis (Taddei et al. 2012). Unlike growth on a plastic cell culture dish, soft agar is a semi-liquid matrix and nontransformed cells are unable to grow, proliferate, and form colonies in the absence of a solid adhesive surface. Moreover, the semiliquid conditions may elicit anoikis of nontransformed cells as they cannot attach to a solid surface. To test whether hnRNP A1 and A2 play redundant or additive roles in transformation, we transduced $\mathrm{HuH} 7$ cells expressing hnRNP A1 shRNA with retroviruses encoding hnRNP A2 shRNA (Supplemental Fig. S2A). HuH7 cells with A1/ A2 double knockdown formed fewer colonies in soft agar, suggesting that hnRNP A1 and A2 have additive and nonredundant roles in transformation (Supplemental Fig. S2B).

Moreover, knockdown of hnRNP A2 did not affect cell cycle distribution while there was a small increase in the number of cells in G1 in hnRNP A1 knockdown cells (Supplemental Fig. S3A-D). We did not observe a significant effect of most hnRNP A1/A2 isoforms on proliferation or cell cycle under normal growth conditions (10\% serum) except for hnRNP A1, which had a small pro-proliferative activity (Fig. 2C; Supplemental Fig. S3A-D). Tumor cells in vivo are exposed to harsh conditions, including low concentrations of nutrients and growth factors. Thus, we examined if hnRNP A1/A1b and/or hnRNP A2/B1 might affect cell growth under low-serum conditions. To explore this possibility, we grew cells under low-serum conditions $(0.1 \%)$ and measured cell number. Knockdown of either hnRNP A1/A1b or hnRNP A2/B1 significantly reduced the growth rate of $\mathrm{HuH} 7$ cells grown under low-serum conditions (Fig. 3D). Notably, we did not detect enhanced apoptosis under these low-serum conditions, suggesting that hnRNP A1 and A2 enable growth under low-nutrient conditions but do not affect cell death under these conditions (Supplemental Fig. S3E,F). We next examined if hnRNP A1/A1b or hnRNP A2/B1 expression is required to maintain transformation in vivo. We injected NOD-SCID mice with $\mathrm{HuH} 7$ cells expressing shRNAs against either hnRNP A1/A1b or hnRNP A2/B1. We found that mice injected with cells knocked down for either hnRNP A1/A1b or hnRNP A2/B1 formed fewer and smaller tumors compared with mice injected with empty vector (Fig. 3E). These results suggest that hnRNP A1 and hnRNP A2 are required for HCC tumor maintenance.

\section{hnRNP A2 activates the Ras-MAPK-ERK pathway}

In order to understand the mechanism by which these splicing factors drive transformation, we investigated the activation of several signal transduction pathways that are known to be involved in cancer development. The Ras-Raf-MEKextracellular signal-regulated kinase (ERK) pathway is frequently activated in cancer, often due to activating mutations in Ras (Downward 2003; Karnoub and Weinberg 2008), 

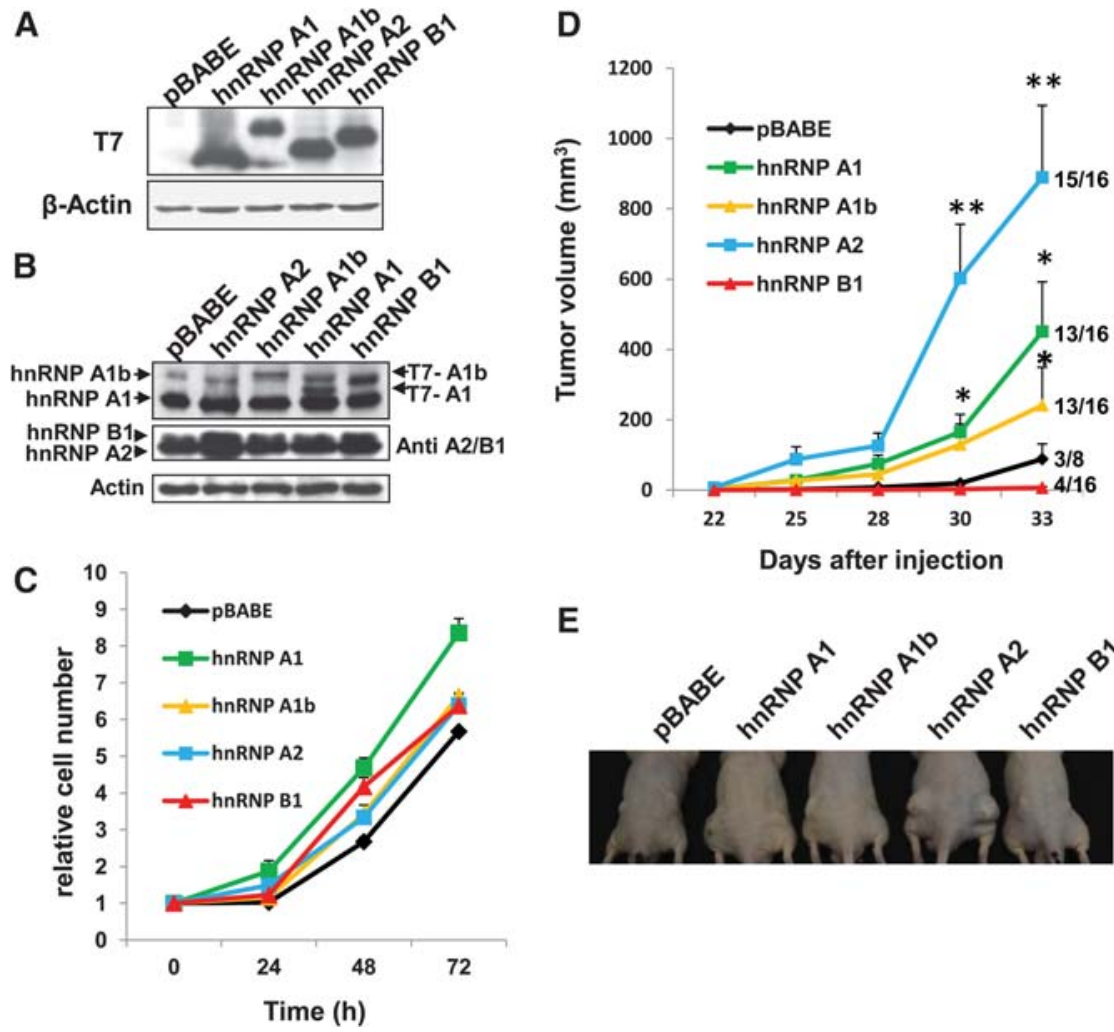

E

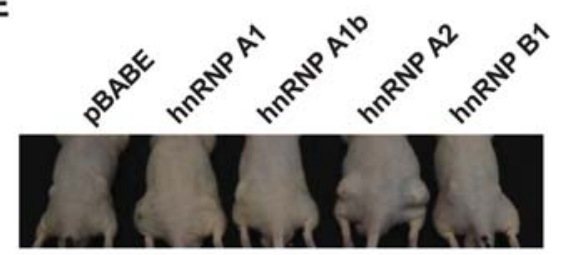

FIGURE 2. hnRNP A1/A1b and A2, but not B1, can transform PHM-1 cells in vivo. $(A, B) \mathrm{PHM}$ 1 cells transduced with retroviruses encoding empty vector ( $\mathrm{pBABE}$ ) or hnRNP A1, A1b, A2, and B1 were analyzed by Western blotting for hnRNP A1/A1b, hnRNP A2/B1, and T7-Tag protein to detect both endogenous and exogenous expression. $\beta$-Actin was used as a loading control. $(C)$ Growth curves of cells described in $A$ were measured by methylene blue staining. Error bars, SD $(n=6)$. (D) Cells described in $A$ were injected $\left(3 \times 10^{6}\right.$ cells/site $)$ subcutaneously near both rear flanks of nude/nude mice, and tumor volume was measured twice weekly (mean \pm SEM; $n=16$ or 8 ). (*) $P<0.05$, (**) $P<0.001$ (two-tailed $t$-test). (E) Representative mice described in $D$ are shown.

B-Raf (Niault and Baccarini 2010; Pratilas and Solit 2010), MEK (Estep et al. 2007; Marks et al. 2008; Nikolaev et al. 2012), or amplification of several of these components (Little et al. 2011). We found that PHM-1 cells overexpressing hnRNP A2, but not its splicing isoform hnRNP B1, showed increased activation of the Ras-MAPK-ERK pathway, as seen by high levels of phospho-ERK1/2 and phosphoMEK1/2 even under low-serum conditions and after stimulation of the pathway by EGF (Fig. 4A; Supplemental Fig. S4A). In contrast, knockdown of hnRNP A2 in HuH7 cells inhibited the Ras-MAPK-ERK pathway and inhibited MEK1 and ERK1/2 activation by EGF (Fig. 4B; Supplemental Fig. S4B). Levels of phospho-ERK1/2 and phospho-MEK1 in hnRNP A1b overexpressing cells were elevated twofold compared with cells expressing the empty vector, while hnRNP A1 did not activate the MAPK-ERK pathway (Fig. 4A; Supplemental Fig. S4B). The differential ability of the isoforms to activate this signal transduction pathway can support a mechanism by which hnRNP A2 can initiate transformation in vivo while hnRNP B1 cannot.

\section{hnRNP A2 regulates the splicing of $A-R a f$ reducing the production of a dominant-negative A-Raf isoform}

Elevated A-Raf expression levels have been observed in a number of malignancies, including astrocytomas (Hagemann et al. 2009), pancreatic ductal carcinoma (Kisanuki et al. 2005), angioimmunoblastic lymphadenopathies (Mark et al. 1986), head and neck squamous cell carcinomas, and colon carcinomas (Rauch et al. 2004, 2010). A recent study reported that $A$-Raf undergoes alternative splicing generating a short isoform which has a dominant-negative effect on A-Raf (Fig. 5A; Rauch et al. 2011). This short isoform, which contains the Ras binding domain and lacks the kinase domain, is predicted to bind to Ras but cannot transmit the signal without the kinase domain. Recently it has been shown that this splicing product is regulated by hnRNP $\mathrm{H}$, a close family member of the hnRNP A/B proteins (Rauch et al. 2011). We examined if the differences we observed in the Ras-MAPK-ERK pathway in cells with hnRNP A2 overexpression or knockdown could be due to altered splicing of A-Raf. We found that in PHM-1 cells expressing hnRNP A2, the mRNA of the short isoform of A-Raf is less abundant while levels of full-length (FL) A-Raf were elevated compared with cells with empty vector (Fig. 5B-D). In contrast, in cells expressing hnRNP B1, the mRNA levels of the short isoform were higher than FL mRNA levels (Fig. 5B,C). Since FL-A-Raf levels were significantly higher in cells overexpressing hnRNPA2, we measured the total level of A-Raftranscripts. Total A-Raf transcript levels were significantly higher (Supplemental Fig. S5), suggesting that other mechanisms, such as enhanced stabilization or transcription of A-Raf, might be affected by hnRNP A2 overexpression. In accordance with higher levels of FL-A-Raf mRNA, we also found elevated FL-A-Raf protein in cells overexpressing hnRNP A2 (Fig. 5D). Moreover, knockdown of hnRNP A2 in $\mathrm{HuH7}$ cells caused the reciprocal change and led to elevation of mRNA levels of the short isoform and down-regulation of FL-A-Raf levels (Fig. 5E). To examine if changes in A-Raf splicing can be detected at the protein level, we performed Western blotting on lysates from $\mathrm{HuH7}$ cells transduced with retroviruses encoding shRNAs against hnRNP A1 or A2 using a specific antibody that can detect the A-Raf short isoform (Rauch et al. 2011). A-Raf short protein was elevated, while the FLA-Raf protein was reduced in $\mathrm{HuH} 7$ cells expressing shRNAs 
A

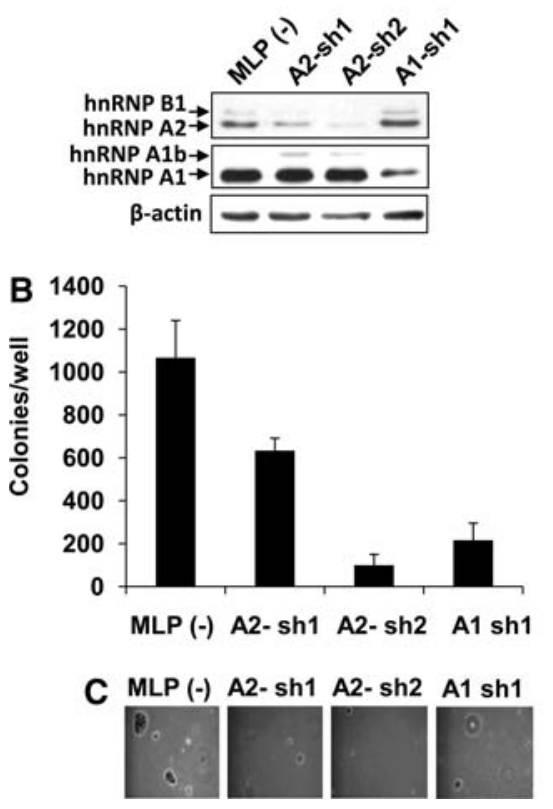

D MLP(-)
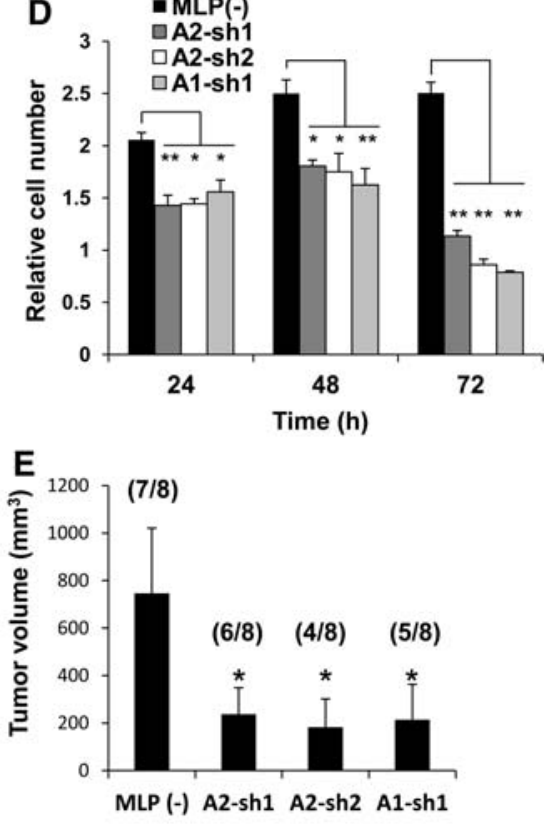

FIGURE 3. hnRNP A2/B1 and hnRNP A1/A1b are required for HCC transformation. (A) HuH7 cells were transduced with retroviruses encoding shRNAs against hnRNP A1/A1b, hnRNP A2/B1, or empty vector without the shRNA (MLP). Cells were analyzed by Western blotting for hnRNP $\mathrm{A} 1 / \mathrm{A} 1 \mathrm{~b}$ and hnRNP A2/B1 protein expression. $\beta$-Actin was used as a loading control. (B) Cells described in $A$ were seeded into soft agar in duplicate, and colonies were grown for $14 \mathrm{~d}$. Colonies in 10 fields of each well were counted (mean \pm SEM; $n=2$ ). (C) Representative fields of colonies in soft agar described in $B$. (D) Cells described in $A$ were starved ( $0.1 \%$ serum), and survival of cells was measured by methylene blue staining (mean \pm SEM; $n=6$ ). $\left({ }^{*}\right) P<0.05,\left({ }^{*}\right) P<0.001$ (twotailed $t$-test). ( $E$ ) Cells described in $A$ were injected $\left(2 \times 10^{6}\right.$ cells/site $)$ subcutaneously near both rear flanks of SCID mice, and a graph depicting tumor growth $29 \mathrm{~d}$ after injection is shown. The number of tumors formed per number of injections is shown in parentheses (mean \pm SEM; $n=8)$. (*) $P<0.05$ (one-tailed $t$-test).

against hnRNP A2 but not hnRNP A1 (Fig. 5F). Taken together these results suggest that A-Raf alternative splicing is regulated by hnRNP A2 and can be detected at both the mRNA and protein level. To further elucidate if hnRNP A2 levels correlate with A-Raf splicing in the mouse HCC tumor mouse model, we measured hnRNPA2 mRNA levels and A-Raf isoform levels in mouse liver normal and tumor tissues. We found that the ratio of FL-A-Raf mRNA to short-A-Raf mRNA was higher in most tumors compared to normal mouse livers (Supplemental Fig. S6A-C). Moreover, there was a positive correlation between hnRNP A2 expression and elevated ratios of FL- to short-A-Raf levels, while no such correlation existed between hnRNP H expression and ratios of A-Raf splicing isoforms (Supplemental Fig. S6D,E). These results suggest that hnRNP A2 up-regulation in tumors can induce an alternative splicing switch in A-Raf.

Inducible expression hnRNP A2 but not B1 can rescue anchorage independent growth and A-Raf splicing after hnRNP A2 knockdown

In order to further understand the roles of each hnRNP A1/A2 isoform in cellular transformation and $A$-Raf splicing, we used a HeLa tet-on inducible system to express each hnRNP A1/A2 isoform on the background of hnRNP A1 or A2 knockdown (Supplemental Fig. S7). This system enables expression of only one isoform in the absence of the other (Supplemental Fig. S7A,B). The shRNAs do not inhibit the expression of the inducible isoforms as they were designed against the $3^{\prime}$ UTR region of the isoform transcripts. Expression of hnRNP A1, but not A1b, could rescue colony formation in soft agar of cells with hnRNP A1/A1b knockdown (Supplemental Fig. S7C). Expression of hnRNP A2, but not B1, could rescue colony formation in soft agar of cells with hnRNP A2/B1 knockdown (Supplemental Fig. S7D). hnRNP A1 expression elevated FL-A-Raf, but did not change the ratio of A-Raf isoforms, and Alb elevated the short A-Raf isoform, suggesting that it might act antagonistically to A1 (Supplemental Fig. S7E, G). hnRNP A2 expression elevated FL-A-Raf and lowered shortA-Raf reciprocally, while hnRNP B1 did not rescue A-Raf splicing in cells with A2/B1 knockdown (Supplemental Fig. S7F,H). It should be noted that expression of hnRNP A1, A1b, and B1 was lower than hnRNP A2, and thus, it is possible that the ability of hnRNP A1 or B1 to rescue colony formation in soft agar and A-Raf splicing would be greater if equal expression was achieved. Since A1b expression was similar to that of A1, this isoform is probably unable to induce transformation or change $A$ Raf splicing as hnRNP A1.

\section{HCC cells with hnRNP A1/A2 overexpression are resistant to apoptosis induced by MEK inhibition}

To clarify the importance of the Ras-MAPK-ERK pathway for the oncogenic potential of HCC cells overexpressing hnRNP A1/A2 proteins, we examined the relationship between hnRNP A1/A2 expression level, activation of the RafMEK-ERK pathway, and sensitivity to a MEK1 inhibitor. Human and mouse immortal (Hc3716-hTERT, PHM-1) cells and HCC cells (BNL-1ME, Hep3B, and FLC-4) showed similar levels of hnRNP A1/A1b and hnRNP A2/B1expression, while $\mathrm{HuH} 7$ and HepG2 HCC cells showed elevated levels of hnRNP A1/A1b and hnRNP A2/B1 proteins (Fig. 6A). $\mathrm{HuH} 7$ and HepG2 cells also showed elevated levels of FLA-Raf protein and strong activation of the Raf-MEK-ERK pathway as measured by MEK1/2 and ERK1/2 phosphorylation (Fig. 6A). We treated the seven human and mouse cell lines with the MEK inhibitor U0126 and measured cell death 
A
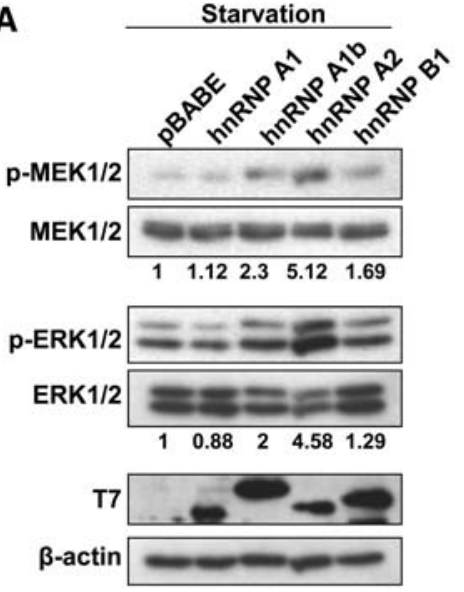

B
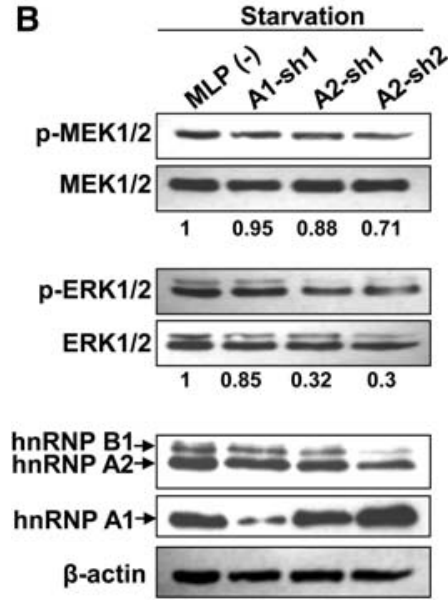
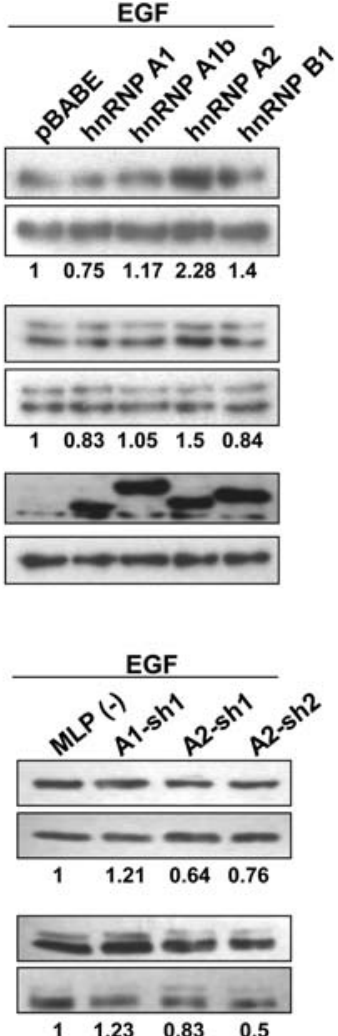

$\begin{array}{llll}1 & 1.23 & 0.83 & 0.5\end{array}$

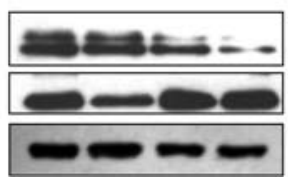

FIGURE 4. hnRNP A2 activates the Ras-MAPK-ERK pathway. $(A, B)$ PHM-1 $(A)$ and HuH7 $(B)$ cells transduced with the indicated retroviruses were seeded in six-well plates $\left(1 \times 10^{5}\right.$ cells/well for PHM- 1 cells, $2 \times 10^{5}$ cells/well for HuH7 cells). Cells were serum-starved for $24 \mathrm{~h}$ $(0.1 \%$ FCS $)$ and stimulated with EGF $(10 \mathrm{nM})$ for $30 \mathrm{~min}$. Cells were lysed and immunoblotted for expression of phosphorylated and total MEK1/2, ERK1/2 and T7-Tag $(A)$ or hnRNP A2/B1 and hnRNP A1/ Alb $(B)$. $\beta$-Actin was used as a loading control. Fold increase of ERK1/2 or MEK1/2 was normalized (phosphorylated/total protein levels) to that of untreated empty vector, which was arbitrarily set at one. Shown here is one representative experiment out of three repeats (see also Supplemental Fig. S4).

induced by MEK inhibition. HuH7 and HepG2 cells, which express higher levels of hnRNP A1 and A2, were resistant to apoptosis induced by the MEK inhibitor U0126. PHM-1, BNL-1ME, Hc3716-hTERT, Hep3B, and FLC-4 cells, which did not have lower levels of hnRNP A1/A2, were more sensitive to MEK inhibitor-induced apoptosis (Fig. 6B,C). Staining for cleaved caspase- 3 confirmed that cell death was due to apoptosis (Fig. 6C). These results suggest that HCC tumors that overexpress hnRNP A1 and A2 might be more resistant to Raf and MEK inhibitors, and thus, hnRNP A1 and A2 levels might serve as a biomarker for resistance to such drugs. To examine if hnRNP A2 mediates the resistance of HuH7 to MEK inhibition, we treated HuH7 cells with or without hnRNP A2 knock-

down with the MEK1 inhibitor U0126. We found that cells with hnRNP A2 knockdown had a modest increase in apoptosis and a significant decrease in total cell number upon treatment with the MEK1 inhibitor U0126 (Fig. 6D,E). These results suggest that hnRNP A2 up-regulation in HCC cancer cells contributes to resistance to MEK1 inhibition.

\section{DISCUSSION}

A growing body of evidence suggests that alternative splicing factors play a major role in cancer development and progression (Karni et al. 2007; Golan-Gerstl et al. 2011; Quesada et al. 2012; Cohen-Eliav et al. 2013). Moreover, genomewide deep sequencing studies conducted recently on several types of cancer or premalignant diseases discovered mutations in splicing factors and suggest that these mutations are driver mutations (Papaemmanuil et al. 2011; Imielinski et al. 2012; Quesada et al. 2012). Furthermore, previous studies from our laboratory and others demonstrated functional oncogenic roles for several splicing factors, including hnRNP A2/B1 (Karni et al. 2007; Golan-Gerstl et al. 2011; Lefave et al. 2011; Cohen-Eliav et al. 2013). Overexpression of hnRNP A1/A2 proteins has been reported in several cancers (Zhou et al. 2001a, 2013; Ushigome et al. 2005; Li et al. 2009; Ma et al. 2009; Boukakis et al. 2010; Wang et al. 2011). In HCC, the splicing factor SRSF1 has been shown to regulate splicing of tumor suppressors such as KLF-6 (Munoz et al. 2012). Splicing factor hnRNP Al was shown to enhance invasiveness and to correlate with metastasis and poor survival in HCC patients (Zhou et al. 2013).

In this study, we examined the oncogenic potential of four isoforms of the hnRNP A1/A2 proteins (hnRNP A1, A1b, $\mathrm{A} 2$, and $\mathrm{B} 1$ ). The differences or redundancies between these isoforms in terms of splicing activity, oncogenic activities, or biological functions are currently unknown. We found that hnRNP A1 and hnRNP A2 are up-regulated in an inflammation-induced HCC mouse model at both the RNA and protein levels (Fig. 1). hnRNP A1 and A2 up-regulation was observed in other types of cancer due to gene amplification (Golan-Gerstl et al. 2011) or transcriptional activation by c-Myc (David et al. 2010). c-Myc is frequently up-regulated in HCC and might be the cause of hnRNP A1 and A2 up-regulation (Tiniakos et al. 1989; Chan et al. 2004). Moreover, transduction of immortal liver progenitors (PHM-1 cells) (Zender et al. 2006) with hnRNP A1 and A2 caused cellular transformation, and these cells were tumorigenic in mice (Fig. 2). Interestingly, hnRNP A2 was more oncogenic than hnRNP A1, but its splicing variant, hnRNP B1 was inactive as an oncogene and could not induce transformation although it is only 36 bases longer (Fig. 2; He and Smith 2009). To examine if hnRNP A1 and A2 are required for tumor maintenance in addition to their oncogenic role in cancer initiation, we knocked down hnRNP A1 and A2 in the human HCC cell line HuH7 (Nakabayashi et al. 1982). We found that knockdown of both genes inhibited colony formation in soft 
A

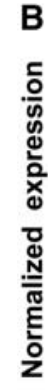

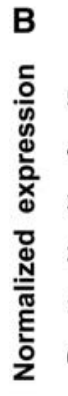

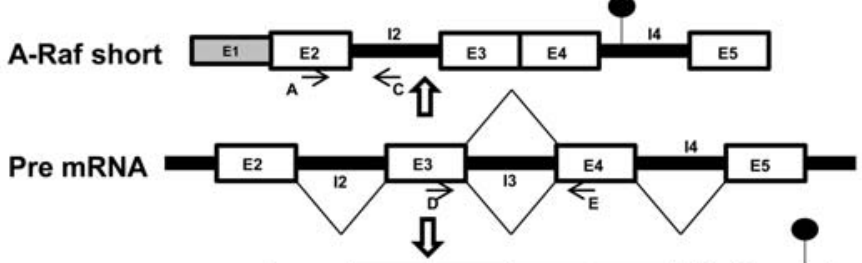

A-Raf Full length

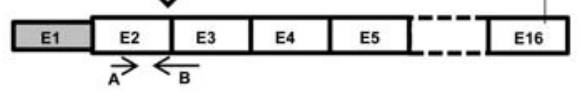

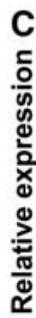

- A-Raf FL 口A-Raf short 3
2
1
0
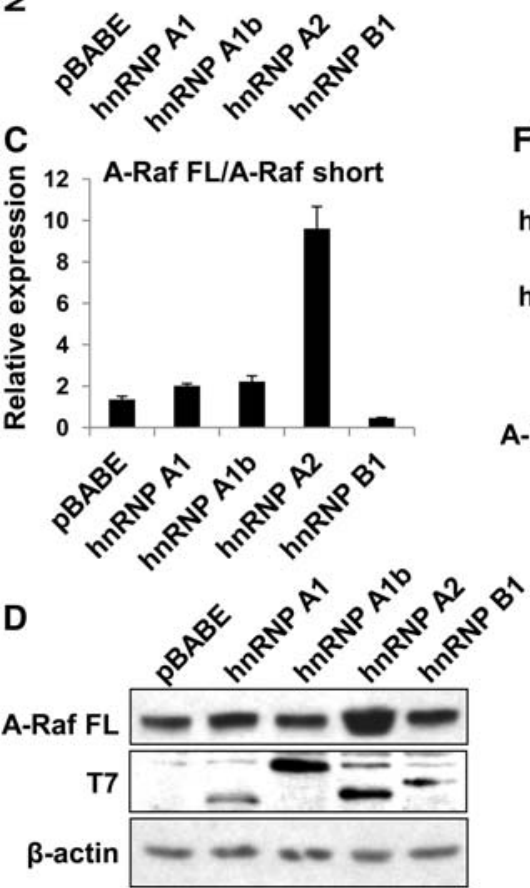

FIGURE 5. hnRNP A2/B1 regulates A-Raf alternative splicing. (A) A diagram showing intronic and exonic regions of $A$-Raf regulated by alternative splicing generating the dominant-negative A-Raf short isoform or the FL transcript. Black lines represent introns, empty boxes represent coding exons, gray boxes represent $5^{\prime}$ UTR, and black circles represent stop codons. Arrows represent primer positions. Primer pair A-B was used to detect A-Raf FL isoform. Primer pair A-C was used to detect A-Raf short isoform. Primer pair D-E was used to detect total A-Raf transcripts (see also Supplemental Fig. S5). (B,C) qRT-PCR analysis of A-Raf mRNA isoform expression $(B)$ or the expression ratio of A-Raf FL/A-Raf short $(C)$ in PHM-1 cells transduced with the indicated retroviruses. All samples were normalized to GAPDH mRNA levels and to the expression of the A-Raf short isoform in control (empty vector, pBABE) cells $(B)$ or to the A-Raf FL/A-Raf short ratio in control (pBABE) cells $(C)$, which was arbitrarily set at one (mean $\pm S E M ; n=3)$. (D) Immunoblot analysis of A-Raf FL and T7-TAG in cells described in $B$ and $C ; \beta$-actin was used as loading control. (E) qRT-PCR analysis of A-Raf isoforms in HuH7 cells transduced with retroviruses encoding for specific shRNAs against either hnRNP A1 or hnRNP A2. All samples were normalized to $\beta$-actin mRNA levels and to the expression of the A-Raf short isoform in control (empty vector without shRNA, MLP) cells, which was arbitrarily set at one (mean \pm SEM; $n=3$ ). $(F)$ Total protein from cells described in $E$ was extracted, and the expression levels of hnRNP A1/ A1b, hnRNP A2/B1, A-Raf FL, and A-Raf short were assessed by Western blotting. $\beta$-Actin was used as a loading control. agar (Fig. 3B,C) and tumorigenesis (Fig. $3 \mathrm{E})$. The tumorigenic effects of hnRNP $\mathrm{A} 1$ and $\mathrm{A} 2$ overexpression (Fig. 2) suggest that they act as proto-oncogenes in HCC development, and the knockdown experiments (Fig. 3) suggest that they are required for tumor maintenance.

Interestingly, hnRNP A2 knockdown or overexpression did not significantly affect cell proliferation under normal growth conditions, while expression of hnRNP A1 had a small positive effect on proliferation (Fig. 2C; Supplemental Fig. S3). To examine if hnRNP A1/A2 knockdown sensitizes HCC cells to stress conditions, we starved $\mathrm{HuH7}$ cells transduced with shRNAs against hnRNP A1 and A2 and measured cell proliferation. Indeed, hnRNP A1 and A2 knockdown decreased HuH7 cells proliferation under serum starvation conditions (Fig. 3D), suggesting that their oncogenic effect might rely on characteristics of transformation such as growth factor-independent proliferation, motility, invasion, and others (Hanahan and Weinberg 2011). Activation of the Ras-Raf-MAPK-ERK signaling pathway is one of the hallmarks of cancer cells, including many HCC tumors. Ras-Raf-MAPK-ERK activation can occur due to Ras or Raf mutations, inactivation of Ras GTPases, or activation of upstream growth factor receptors (Challen et al. 1992; Hopfner et al. 2004; Calvisi et al. 2006, 2011; Colombino et al. 2012). We examined if hnRNP A1, A2, or their isoforms affect the activity of this pathway. We found that in correlation with its oncogenic potential, hnRNP A2 was the strongest activator of the RasMAPK-ERK pathway as measured by MEK1 and ERK phosphorylation, while its isoform hnRNP B1 did not activate this pathway at all (Fig. 4A). Knockdown of hnRNP A2 prevented MEK1 and ERK1/2 activation by EGF, suggesting that hnRNP A2 is required for activation of this pathway in HCC cells (Fig. 4B). Notably, hnRNP Alb seems to be a weak activator of the Ras-MAPK-ERK pathway, while hnRNP A1 did not affect the MEK-ERK pathway (Fig. 4). Recent studies showed that upon c-Myc up-regulation, A-Raf is alternatively spliced to reduce a dominant-negative short isoform 
A

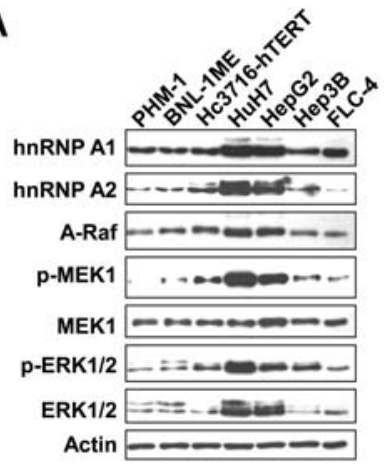

B

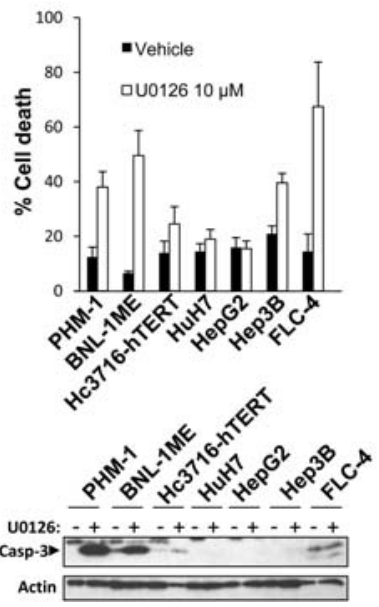

FIGURE 6. Sensitivity of HCC cells to MEK inhibitor-induced apoptosis correlates with hnRNP A1 and A2 levels. (A) Cells were lysed, and protein levels of hnRNP A2/B1, hnRNP A1/A1b, A-Raf FL and total and phosphorylated MEK1/2 and ERK1/2 were examined using Western blot. $\beta$-Actin was used as loading control. (B) HCC cell lines were treated either with vehicle or MEK inhibitor U0126 $(10 \mu \mathrm{M})$ for $24 \mathrm{~h}$ and subjected to trypan blue exclusion assay. $(C)$ Cells described in $A$ and $B$ were analyzed by Western blot for cleaved caspase-3, a marker for apoptosis. $\beta$-Actin served as loading control. (D) HuH7 cells transduced with the indicated retroviruses were seeded $\left(120 \times 10^{4}\right.$ cells/well in a six-well plate in triplicates) and treated with either vehicle or MEK inhibitor U0126 $(10 \mu \mathrm{M})$ for $48 \mathrm{~h}$ and subjected to trypan blue exclusion assay. $\left(^{*}\right)$ Increased apoptosis after U0126 treatment in hnRNP A2 knockdown compared with MLP. $P=0.053$. (E) Cells described in $D$ were counted (total cell number) by a BioRad cell counter. ${ }^{*}$ ) Reduced cell number after U0126 treatment in hnRNP A2 knockdown compared with MLP. $P=0.033$. Experiments described in $D$ and $E$ were repeated at least twice.

and up-regulate the transcript encoding active A-Raf (Rauch et al. 2010, 2011). We examined if hnRNP A1, A2, or their splicing isoforms affect $A$-Raf alternative splicing, and we found that hnRNP A1, A1b, and A2 down-regulated the dominant-negative short A-Raf isoform, while hnRNP B1 did not (Fig. 5). hnRNP A2 overexpression induced elevated levels of FL-A-Raf beyond a reciprocal change in alternative splicing, suggesting that it might also affect mRNA stability or transcription of A-Raf transcripts (Fig. 5B; Supplemental Fig. S5). These results suggest that hnRNP A2 activates the RasRaf-MEK-ERK pathway by its effect on A-Raf splicing downstream from Ras (Fig. 5; Supplemental Fig. S7).
To further pinpoint the roles of each hnRNP A1/A2 isoform in cellular transformation and A-Raf splicing, we used a HeLa tet-on inducible system to express each hnRNP A1/ $\mathrm{A} 2$ isoform on the background of hnRNP A1 or A2 knockdown. This system enables expression of one isoform while the other is absent (Supplemental Fig. S7). Results from the inducible system show that hnRNP A2, but not B1, expression can rescue colony formation in soft agar and ARaf splicing (Supplemental Fig. S7). hnRNP A1 could partially rescue colony formation but not $A$-Rafsplicing. Expression of hnRNP A1 and A1b was lower than hnRNP A2, and thus, it is possible that the ability of hnRNP Al to rescue colony formation and $A$-Raf splicing is greater if equal expression was achieved.

To examine if activation of the Raf-MEK-ERK pathway plays a role in the oncogenic activity of cells overexpressing hnRNP A1 and A2, we treated seven human and mouse HCC cell lines with the MEK inhibitor U0126 and measured cell death induced by MEK inhibition. Surprisingly, HuH7 and HepG2 cells that express high levels of hnRNP A1 and A2 showed elevated FL-A-Raf levels, enhanced phosphorylation of MEK1/2 and ERK 1/2, and were resistant to apoptosis induced by the MEK inhibitor U0126 (Fig. 6). To examine if hnRNP A2 mediates the resistance of HuH7 cells to MEK1 inhibition, we treated $\mathrm{HuH7}$ cells with or without hnRNP A2 knockdown with the MEK1 inhibitor U0126. Since hnRNP A2 knockdown reduced cell proliferation upon treatment with the MEK1 inhibitor U0126 (Fig. 6), the results suggest that hnRNP A2 up-regulation in HCC cells contributes to resistance to MEK1 inhibition. Thus, hnRNP A2 up-regulation might serve as a biomarker for resistance to Raf-MEK inhibitors and as a new target for resensitization of HCC tumors resistant to MEK1 inhibitors.

Taken together, our data suggest that hnRNP A1 and more profoundly hnRNP A2 up-regulation in HCC tumors induces an alternative splicing switch that down-regulates a dominant-negative isoform of A-Raf and up-regulation of the FLA-Raf, leading to activation of the Raf-MEK-ERK pathway (Figs. 5, 6). Another implication for these results is that tumors overexpressing hnRNP A1 and A2 might be more resistant to Raf, MEK1, or ERK inhibitors.

\section{MATERIALS AND METHODS}

\section{Mice}

Mice with a homozygous disruption of the Mdr2 gene, Mdr2 $2^{-1-}$ (Jackson Laboratory, stock no. 002539), with a FVB/N genetic background were used. Liver tumors were derived from 14-moold $M d r 2^{-1-}$ mice. Age-matched FVB/N mice were used as a source for normal liver tissue. Animals were killed by a lethal dose of anesthesia. Mice were held in specific pathogen-free conditions. All animal experiments were performed in accordance with the guidelines of the Hebrew University committee for the use of animals for research. 


\section{Cells}

Liver progenitor cells from embryonic day 18 fetal livers from $\mathrm{TP}^{-1-}$ mice were isolated and immortalized with MSCV-based retroviruses expressing Myc-IRES-GFP as previously described (Zender et al. 2006) to generate TP53 ${ }^{-/-}$hepatocytes myc (PHM1) cells. PHM-1, HuH7, HepG2, Hep3B FLC-4, BNL-1ME, Hc3716-hTERT (Waki et al. 2010), and HeLa Tet-on (Clontech) cells were grown in DMEM supplemented with 10\% FCS, $2 \mathrm{mM}$ L-glutamine, $0.1 \mathrm{mg} / \mathrm{mL}$ penicillin, and $0.1 \mathrm{mg} / \mathrm{mL}$ streptomycin. All cell lines have been tested and authenticated by the biosynthesis DNA Identity Testing Center on July 29, 2013.

\section{Stable cell lines}

To generate stable cell lines, PHM-1 and HeLa Tet-on cells were transduced with-pBABE-puro or STP-puro retroviral vectors, respectively, expressing T7-tagged hnRNP A1, hnRNP Alb, hnRNP A2, or hnRNP B1 cDNA. Medium was replaced $24 \mathrm{~h}$ after infection, and 24 h later, infected cells were selected with puromycin $(2 \mu \mathrm{g} / \mathrm{mL})$ for $72 \mathrm{~h}$. Stable pools of HeLa Tet-on cell lines were transduced with pSin-Hygro-miR30-shRNA vectors (Narita et al. 2006). Medium was replaced $24 \mathrm{~h}$ after infection, and $24 \mathrm{~h}$ later, infected cells were selected for with hygromycin $(200 \mu \mathrm{g} / \mathrm{mL})$ for $72 \mathrm{~h}$. shRNA sequences are as follows: HNRNP A2/B1-sh2, CCA TGGGCTTCACTGTATA; HNRNP A1-sh1, GACTGTATTTGTGA CTAAT. In the case of infection with MLP-puro-shRNA vectors, $\mathrm{HuH} 7$ cell transductants were selected with puromycin $(2 \mu \mathrm{g} / \mathrm{mL})$ for $96 \mathrm{~h}$. shRNA sequences are as follows: HNRNP A2/B1-sh1, CTGTTTGTTGGCGGAATTA; sh2, CCATGGGCTTCACTGTA TA; and HNRNP A1-sh1, GACTGTATTTGTGACTAAT.

\section{EGF stimulation}

We seeded $8 \times 10^{5}$ PHM- 1 or $1.2 \times 10^{6} \mathrm{HuH} 7$ cells in $10-\mathrm{cm}$ plates. Twenty-four hours later, cells were washed with PBS, and medium was replaced with medium containing $0.1 \%$ serum for $24 \mathrm{~h}$. Cells were stimulated with EGF $50 \mathrm{ng} / \mathrm{mL}$ for $30 \mathrm{~min}$, after which, cells were lysed in Laemmli buffer for Western blot analysis.

\section{Immunoblotting}

Cells were lysed in Laemmli buffer and analyzed for total protein concentration as described (Karni et al. 2007). Fifty micrograms of total protein from each cell lysate was separated by SDS-PAGE and transferred onto a nitrocellulose membrane. The membranes were blocked with $5 \%$ milk and probed with specific antibodies. Bands were visualized using enhanced chemiluminescence detection. Primary antibodies are as follows: hnRNP A1 (mAb A1/55, 1:1000) (Allemand et al. 2005), hnRNP A2/B1 (1:1000, Santa Cruz), $\beta$-tubulin (1:1000, Sigma), $\beta$-catenin (1:2000, Sigma), $\beta$-actin (1:1000, Santa Cruz), T7 tag (1:5000, Novagen), phosphoMEK S217/221 (1:1000, Cell Signaling), total MEK (1:1000, Cell Signaling), phospho-ERK T202/Y204 (1:1000 Sigma), total ERK1/ 2 (1:1000, Cell Signaling), A-Raf (1:1000, Cell Signaling), and ARaf short (1:500) (Rauch et al. 2011). Secondary antibodies are as follows: HRP-conjugated goat anti-mouse, goat anti-rabbit, donkey anti-goat IgG (H+L; 1:10,000 Jackson Laboratories).

\section{Anchorage-independent growth}

Colony formation in soft agar was assayed as described previously (Karni et al. 2007). In the case of HeLa Tet-on cell lines, $5 \mu \mathrm{g} / \mathrm{mL}$ doxycycline (Dox) was added to the top media. Plates were incubated at $37^{\circ} \mathrm{C}$ with $5 \% \mathrm{CO}_{2}$. After $10-21 \mathrm{~d}$, colonies were counted from 10 different fields in each of two wells for each transductant pool, and the average number of colonies per well was calculated. The colonies were stained as described (Karni et al. 2007) and photographed under a light microscope at $100 \times$ magnification.

\section{Growth curves}

Transductant pools of PHM-1 cells were seeded at 1800 cells per well in 96-well plates. Every $24 \mathrm{~h}$, cells were fixed and stained with methylene blue as described previously (Karni et al. 2007), and the absorbance at $650 \mathrm{~nm}$ of the acid-extracted stain was measured by a plate reader (BioRad).

\section{Survival and apoptosis assays}

HuH7 cells were transduced with the indicated retroviruses. Following selection, 4500 cells per well were seeded in 96-well plates. Twenty-four hours later, the medium was replaced to medium containing $0.1 \%$ serum. At $24 \mathrm{~h}$ (before treatment), one 96-plate was fixed and served as a normalizing control (“Time 0"). Every 24 h, cells were fixed and stained with methylene blue as described previously (Karni et al. 2007) and the absorbance at $650 \mathrm{~nm}$ of the acidextracted stain was measured by a plate reader (BioRad) and normalized to cell absorbance at Time 0. HCC cells were seeded in six-well plates $\left(2 \times 10^{5}\right.$ cells/well $)$. Twenty-four hours later, cells were incubated with $10 \mu \mathrm{M}$ U0126 for $24 \mathrm{~h}$. Medium and PBS washes were collected together with cells trypsinized from each well into $15-\mathrm{mL}$ tubes and centrifuged at $1000 \mathrm{~g}$ for $5 \mathrm{~min}$. Cells were washed with PBS and after centrifugation were resuspended in $100 \mu \mathrm{L}$ of PBS. Ten microliters of the cell suspension was mixed with $10 \mu \mathrm{L}$ of $4 \%$ trypan blue solution, and live/dead cells were counted in Bio-Rad TC-10 automated cell counter. After counting, the remaining $90 \mu \mathrm{L}$ of cell suspension was centrifuged, and cells were resuspended in $90 \mu \mathrm{L}$ of Laemmli buffer. Lysates were separated on SDS-PAGE, and after Western blotting, membranes were probed with antibodies against cleaved caspase- 3 to evaluate induction of apoptosis.

\section{Quantitative RT-PCR}

Total RNA was extracted with Tri reagent (Sigma), and $2 \mu \mathrm{g}$ of total RNA was reverse transcribed using the M-MLV reverse transcriptase (Promega) after DNase treatment (Promega). qPCR was performed on the cDNA using SYBR green (Roche) and the CFX96 (Bio-Rad) real-time PCR machine. mRNA levels of hnRNP A1 and hnRNP A2 were measured in mouse normal liver and tumor tissues. mRNA levels of A-Raf isoforms were measured in liver cell lines PHM-1 and $\mathrm{HuH} 7$ and in HeLA Tet-on cell lines. Normalization was performed using either GAPDH for mouse samples and PHM-1 cells or $\beta$-actin for human HuH7 and HeLa Tet-on cells. Unknown samples were compared to a standard curve, which was established by serial dilutions of a known concentration of cDNA. The PCR reaction is composed of the following steps: one cycle for $10 \mathrm{sec}$ at $95^{\circ} \mathrm{C}$ 
and $40 \mathrm{cycles}$ of $5 \mathrm{sec}$ at $95^{\circ} \mathrm{C}$ and $20 \mathrm{sec}$ at $55^{\circ} \mathrm{C}$. Primers are listed in Supplemental Table S1.

\section{Xenograft tumor formation in mice}

Stable pools of PHM-1 cells expressing hnRNP A1, hnRNP Alb, hnRNP A2, or hnRNP B1were injected $\left(3 \times 10^{6}\right.$ cells/site in 200 $\mu \mathrm{L}$ PBS) subcutaneously into each rear flank of nude mice using a 26-gauge needle. Tumor growth was monitored biweekly. HuH7 cells expressing specific shRNAs were injected $\left(2 \times 10^{6}\right.$ cells/site in $200 \mu \mathrm{L}$ PBS) subcutaneously near both rear flanks of SCID mice using a 26-gauge needle. Tumor volume was measured twice a week.

\section{SUPPLEMENTAL MATERIAL}

Supplemental material is available for this article.

\section{ACKNOWLEDGMENTS}

We thank Prof. Oded Meyuhas and Dr. Zahava Kluger for comments on the manuscript and members of the Karni laboratory for helpful discussions. This work was supported by the Israeli Science Foundation (ISF Grants no. 780/08 and 1290/12 to R.K.), ICRF RCDA grant (to R.K.). and MINERVA stiftung ARCHES award from BMBF, Germany (to R.K. and L.Z.). W.K. and J.R. were funded by the Science Foundation Ireland grant 06/CE/B1129.

Author contributions: A.S. and R.K. designed the experiments. A.S., V.B.H., P.D., and I.S. performed experiments. L.Z., E.P., J.R., and W.K. contributed reagents and technical help. A.S. and R.K. analyzed the data and wrote the manuscript.

Received August 30, 2013; accepted January 22, 2014.

\section{REFERENCES}

Allemand E, Guil S, Myers M, Moscat J, Caceres JF, Krainer AR. 2005. Regulation of heterogenous nuclear ribonucleoprotein A1 transport by phosphorylation in cells stressed by osmotic shock. Proc Natl Acad Sci 102: 3605-3610.

Anczukow O, Rosenberg AZ, Akerman M, Das S, Zhan L, Karni R, Muthuswamy SK, Krainer AR. 2012. The splicing factor SRSF1 regulates apoptosis and proliferation to promote mammary epithelial cell transformation. Nat Struct Mol Biol 19: 220-228.

Blanchette M, Chabot B. 1997. A highly stable duplex structure sequesters the $5^{\prime}$ splice site region of hnRNP Al alternative exon 7B. RNA 3: 405-419.

Boukakis G, Patrinou-Georgoula M, Lekarakou M, Valavanis C, Guialis A. 2010. Deregulated expression of hnRNP A/B proteins in human non-small cell lung cancer: Parallel assessment of protein and mRNA levels in paired tumour/non-tumour tissues. BMC Cancer 10: 434.

Burd CG, Swanson MS, Gorlach M, Dreyfuss G. 1989. Primary structures of the heterogeneous nuclear ribonucleoprotein $\mathrm{A} 2, \mathrm{~B} 1$, and C2 proteins: A diversity of RNA binding proteins is generated by small peptide inserts. Proc Natl Acad Sci 86: 9788-9792.

Buvoli M, Cobianchi F, Bestagno MG, Mangiarotti A, Bassi MT, Biamonti G, Riva S. 1990. Alternative splicing in the human gene for the core protein Al generates another hnRNP protein. EMBO J 9: 1229-1235.

Calvisi DF, Ladu S, Gorden A, Farina M, Conner EA, Lee JS, Factor VM, Thorgeirsson SS. 2006. Ubiquitous activation of Ras and Jak/Stat pathways in human HCC. Gastroenterology 130: 1117-1128.
Calvisi DF, Ladu S, Conner EA, Seo D, Hsieh JT, Factor VM, Thorgeirsson SS. 2011. Inactivation of Ras GTPase-activating proteins promotes unrestrained activity of wild-type Ras in human liver cancer. J Hepatol 54: 311-319.

Challen C, Guo K, Collier JD, Cavanagh D, Bassendine MF. 1992. Infrequent point mutations in codons 12 and 61 of ras oncogenes in human hepatocellular carcinomas. J Hepatol 14: 342-346.

Chan KL, Guan XY, Ng IO. 2004. High-throughput tissue microarray analysis of c-myc activation in chronic liver diseases and hepatocellular carcinoma. Hum Pathol 35: 1324-1331.

Clower CV, Chatterjee D, Wang Z, Cantley LC, Vander Heiden MG, Krainer AR. 2010. The alternative splicing repressors hnRNP A1/ A2 and PTB influence pyruvate kinase isoform expression and cell metabolism. Proc Natl Acad Sci 107: 1894-1899.

Cohen-Eliav M, Golan-Gerstl R, Siegfried Z, Andersen CL, Thorsen K, Orntoft TF, Mu D, Karni R. 2013. The splicing factor SRSF6 is amplified and is an oncoprotein in lung and colon cancers. J Pathol 229: 630-639.

Colombino M, Sperlongano P, Izzo F, Tatangelo F, Botti G, Lombardi A, Accardo M, Tarantino L, Sordelli I, Agresti M, et al. 2012. BRAF and PIK3CA genes are somatically mutated in hepatocellular carcinoma among patients from South Italy. Cell Death Dis 3: e259.

Cooper TA, Wan L, Dreyfuss G. 2009. RNA and disease. Cell 136: 777-793.

David CJ, Manley JL. 2010. Alternative pre-mRNA splicing regulation in cancer: Pathways and programs unhinged. Genes Dev 24: 2343-2364.

David CJ, Chen M, Assanah M, Canoll P, Manley JL. 2010. HnRNP proteins controlled by c-Myc deregulate pyruvate kinase mRNA splicing in cancer. Nature 463: 364-368.

Downward J. 2003. Targeting RAS signalling pathways in cancer therapy. Nat Rev Cancer 3: 11-22.

Dreyfuss G, Kim VN, Kataoka N. 2002. Messenger-RNA-binding proteins and the messages they carry. Nat Rev Mol Cell Biol 3: 195-205.

Estep AL, Palmer C, McCormick F, Rauen KA. 2007. Mutation analysis of BRAF, MEK1 and MEK2 in 15 ovarian cancer cell lines: Implications for therapy. PLoS One 2: e1279.

Fielding P, Turnbull L, Prime W, Walshaw M, Field JK. 1999. Heterogeneous nuclear ribonucleoprotein A2/B1 up-regulation in bronchial lavage specimens: A clinical marker of early lung cancer detection. Clin Cancer Res 5: 4048-4052.

Finkin S, Pikarsky E. 2011. NF-kB in liver cancer: The plot thickens. Curr Top Microbiol Immunol 349: 185-196.

Golan-Gerstl R, Cohen M, Shilo A, Suh SS, Bakacs A, Coppola L, Karni R. 2011. Splicing factor hnRNP A2/B1 regulates tumor suppressor gene splicing and is an oncogenic driver in glioblastoma. Cancer Res 71: 4464-4472.

Hagemann C, Gloger J, Anacker J, Said HM, Gerngras S, Kuhnel S, Meyer C, Rapp UR, Kammerer U, Vordermark D, et al. 2009. RAF expression in human astrocytic tumors. Int J Mol Med 23: 17-31.

Hanahan D, Weinberg RA. 2011. Hallmarks of cancer: The next generation. Cell 144: 646-674.

Hanamura A, Caceres JF, Mayeda A, Franza BR Jr, Krainer AR. 1998. Regulated tissue-specific expression of antagonistic pre-mRNA splicing factors. RNA 4: 430-444.

He G, Karin M. 2011. NF- $\mathrm{BB}$ and STAT3: Key players in liver inflammation and cancer. Cell Res 21: 159-168.

He Y, Smith R. 2009. Nuclear functions of heterogeneous nuclear ribonucleoproteins A/B. Cell Mol Life Sci 66: 1239-1256.

Hopfner M, Sutter AP, Huether A, Schuppan D, Zeitz M, Scherubl H. 2004. Targeting the epidermal growth factor receptor by gefitinib for treatment of hepatocellular carcinoma. J Hepatol 41: $1008-1016$

Imielinski M, Berger AH, Hammerman PS, Hernandez B, Pugh TJ, Hodis E, Cho J, Suh J, Capelletti M, Sivachenko A, et al. 2012. Mapping the hallmarks of lung adenocarcinoma with massively parallel sequencing. Cell 150: 1107-1120.

Jia R, Li C, McCoy JP, Deng CX, Zheng ZM. 2010. SRp20 is a proto-oncogene critical for cell proliferation and tumor induction and maintenance. Int J Biol Sci 6: 806-826. 
Karni R, de Stanchina E, Lowe SW, Sinha R, Mu D, Krainer AR. 2007. The gene encoding the splicing factor SF2/ASF is a proto-oncogene. Nat Struct Mol Biol 14: 185-193.

Karnoub AE, Weinberg RA. 2008. Ras oncogenes: Split personalities. Nat Rev Mol Cell Biol 9: 517-531.

Kim E, Goren A, Ast G. 2008. Insights into the connection between cancer and alternative splicing. Trends Genet 24: 7-10.

Kisanuki H, Choi YL, Wada T, Moriuchi R, Fujiwara S, Kaneda R, Koinuma K, Ishikawa M, Takada S, Yamashita Y, et al. 2005. Retroviral expression screening of oncogenes in pancreatic ductal carcinoma. Eur J Cancer 41: 2170-2175.

Lefave CV, Squatrito M, Vorlova S, Rocco GL, Brennan CW, Holland EC, Pan YX, Cartegni L. 2011. Splicing factor hnRNPH drives an oncogenic splicing switch in gliomas. EMBO J 30: 40844097.

Li S, Xu H, Ding H, Huang Y, Cao X, Yang G, Li J, Xie Z, Meng Y, Li X, et al. 2009. Identification of an aptamer targeting hnRNP A1 by tissue slide-based SELEX. J Pathol 218: 327-336.

Little AS, Balmanno K, Sale MJ, Newman S, Dry JR, Hampson M, Edwards PA, Smith PD, Cook SJ. 2011. Amplification of the driving oncogene, KRAS or BRAF, underpins acquired resistance to MEK1/2 inhibitors in colorectal cancer cells. Sci Signal 4: ra17.

Ma YL, Peng JY, Zhang P, Huang L, Liu WJ, Shen TY, Chen HQ, Zhou YK, Zhang M, Chu ZX, et al. 2009. Heterogeneous nuclear ribonucleoprotein $\mathrm{Al}$ is identified as a potential biomarker for colorectal cancer based on differential proteomics technology. J Proteome Res 8: 4525-4535.

Mark GE, Seeley TW, Shows TB, Mountz JD. 1986. pks, a raf-related sequence in humans. Proc Natl Acad Sci 83: 6312-6316.

Marks JL, Gong Y, Chitale D, Golas B, McLellan MD, Kasai Y, Ding L, Mardis ER, Wilson RK, Solit D, et al. 2008. Novel MEK1 mutation identified by mutational analysis of epidermal growth factor receptor signaling pathway genes in lung adenocarcinoma. Cancer Res 68: 5524-5528.

Munoz U, Puche JE, Hannivoort R, Lang UE, Cohen-Naftaly M, Friedman SL. 2012. Hepatocyte growth factor enhances alternative splicing of the Kruppel-like factor 6 (KLF6) tumor suppressor to promote growth through SRSF1. Mol Cancer Res 10: 1216-1227.

Nakabayashi H, Taketa K, Miyano K, Yamane T, Sato J. 1982. Growth of human hepatoma cells lines with differentiated functions in chemically defined medium. Cancer Res 42: 3858-3863.

Narita M, Krizhanovsky V, Nunez S, Chicas A, Hearn SA, Myers MP, Lowe SW. 2006. A novel role for high-mobility group a proteins in cellular senescence and heterochromatin formation. Cell 126: 503-514.

Niault TS, Baccarini M. 2010. Targets of Raf in tumorigenesis. Carcinogenesis 31: 1165-1174.

Nikolaev SI, Rimoldi D, Iseli C, Valsesia A, Robyr D, Gehrig C, Harshman K, Guipponi M, Bukach O, Zoete V, et al. 2012. Exome sequencing identifies recurrent somatic MAP2K1 and MAP2K2 mutations in melanoma. Nat Genet 44: 133-139.

Papaemmanuil E, Cazzola M, Boultwood J, Malcovati L, Vyas P, Bowen D, Pellagatti A, Wainscoat JS, Hellstrom-Lindberg E, Gambacorti-Passerini C, et al. 2011. Somatic SF3B1 mutation in myelodysplasia with ring sideroblasts. N Engl J Med 365: 1384-1395.

Patry C, Bouchard L, Labrecque P, Gendron D, Lemieux B, Toutant J, Lapointe E, Wellinger R, Chabot B. 2003. Small interfering RNAmediated reduction in heterogeneous nuclear ribonucleoparticule A1/A2 proteins induces apoptosis in human cancer cells but not in normal mortal cell lines. Cancer Res 63: 7679-7688.

Pikarsky E, Porat RM, Stein I, Abramovitch R, Amit S, Kasem S, Gutkovich-Pyest E, Urieli-Shoval S, Galun E, Ben-Neriah Y. 2004. $\mathrm{NF}-\kappa \mathrm{B}$ functions as a tumour promoter in inflammation-associated cancer. Nature 431: 461-466.

Pratilas CA, Solit DB. 2010. Targeting the mitogen-activated protein kinase pathway: Physiological feedback and drug response. Clin Cancer Res 16: 3329-3334.

Quesada V, Conde L, Villamor N, Ordonez GR, Jares P, Bassaganyas L, Ramsay AJ, Bea S, Pinyol M, Martinez-Trillos A, et al. 2012. Exome sequencing identifies recurrent mutations of the splicing factor SF3B1 gene in chronic lymphocytic leukemia. Nat Genet 44: 47-52.

Rauch J, Ahlemann M, Schaffrik M, Mack B, Ertongur S, Andratschke M, Zeidler R, Lang S, Gires O. 2004. Allogenic antibodymediated identification of head and neck cancer antigens. Biochem Biophys Res Commun 323: 156-162.

Rauch J, O’Neill E, Mack B, Matthias C, Munz M, Kolch W, Gires O. 2010. Heterogeneous nuclear ribonucleoprotein H blocks MST2mediated apoptosis in cancer cells by regulating $a$-raf transcription. Cancer Res 70: 1679-1688.

Rauch J, Moran-Jones K, Albrecht V, Schwarzl T, Hunter K, Gires O, Kolch W. 2011. c-Myc regulates RNA splicing of the A-Raf kinase and its activation of the ERK pathway. Cancer Res 71: 4664-4674.

Roy M, Xu Q, Lee C. 2005. Evidence that public database records for many cancer-associated genes reflect a splice form found in tumors and lack normal splice forms. Nucleic Acids Res 33: 50265033.

Shimoni-Sebag A, Lebenthal-Loinger I, Zender L, Karni R. 2013. RRM1 domain of the splicing oncoprotein SRSF1 is required for MEK1MAPK-ERK activation and cellular transformation. Carcinogenesis 34: 2498-2504.

Shiraha H, Yamamoto K, Namba M. 2013. Human hepatocyte carcinogenesis (review). Int J Oncol 42: 1133-1138.

Srebrow A, Kornblihtt AR. 2006. The connection between splicing and cancer. J Cell Sci 119: 2635-2641.

Taddei ML, Giannoni E, Fiaschi T, Chiarugi P. 2012. Anoikis: An emerging hallmark in health and diseases. J Pathol 226: 380-393.

Tiniakos D, Spandidos DA, Kakkanas A, Pintzas A, Pollice L, Tiniakos G. 1989. Expression of ras and myc oncogenes in human hepatocellular carcinoma and non-neoplastic liver tissues. Anticancer Res 9: 715721.

Ushigome M, Ubagai T, Fukuda H, Tsuchiya N, Sugimura T, Takatsuka J, Nakagama H. 2005. Up-regulation of hnRNP Al gene in sporadic human colorectal cancers. Int J Oncol 26: 635-640.

Venables JP. 2004. Aberrant and alternative splicing in cancer. Cancer Res 64: 7647-7654.

Venables JP, Klinck R, Koh C, Gervais-Bird J, Bramard A, Inkel L, Durand M, Couture S, Froehlich U, Lapointe E, et al. 2009. Cancer-associated regulation of alternative splicing. Nat Struct Mol Biol 16: 670-676.

Waki K, Anno K, Ono T, Ide T, Chayama K, Tahara H. 2010. Establishment of functional telomerase immortalized human hepatocytes and a hepatic stellate cell line for telomere-targeting anticancer drug development. Cancer Sci 101: 1678-1685.

Wang L, Liu HL, Li Y, Yuan P. 2011. Proteomic analysis of pancreatic intraepithelial neoplasia and pancreatic carcinoma in rat models. World J Gastroenterol 17: 1434-1441.

Xi L, Feber A, Gupta V, Wu M, Bergemann AD, Landreneau RJ, Litle VR, Pennathur A, Luketich JD, Godfrey TE. 2008. Whole genome exon arrays identify differential expression of alternatively spliced, cancer-related genes in lung cancer. Nucleic Acids Res 36: 6535-6547.

Zender L, Spector MS, Xue W, Flemming P, Cordon-Cardo C, Silke J, Fan ST, Luk JM, Wigler M, Hannon GJ, et al. 2006. Identification and validation of oncogenes in liver cancer using an integrative oncogenomic approach. Cell 125: 1253-1267.

Zhou J, Allred DC, Avis I, Martinez A, Vos MD, Smith L, Treston AM, Mulshine JL. 2001a. Differential expression of the early lung cancer detection marker, heterogeneous nuclear ribonucleoprotein-A2/B1 (hnRNP-A2/B1) in normal breast and neoplastic breast cancer. Breast Cancer Res Treat 66: 217-224.

Zhou J, Nong L, Wloch M, Cantor A, Mulshine JL, Tockman MS. 2001b. Expression of early lung cancer detection marker: hnRNP$\mathrm{A} 2 / \mathrm{B} 1$ and its relation to microsatellite alteration in non-small cell lung cancer. Lung Cancer 34: 341-350.

Zhou ZJ, Dai Z, Zhou SL, Fu XT, Zhao YM, Shi YH, Zhou J, Fan J. 2013. Overexpression of HnRNP Al promotes tumor invasion through regulating CD44v6 and indicates poor prognosis for hepatocellular carcinoma. Int J Cancer 132: 1080-1089. 

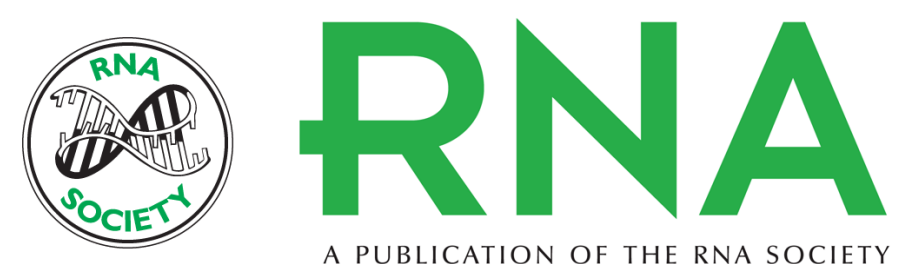

A PUBLICATION OF THE RNA SOCIETY

\section{Splicing factor hnRNP A2 activates the Ras-MAPK-ERK pathway by controlling A-Raf splicing in hepatocellular carcinoma development}

Asaf Shilo, Vered Ben Hur, Polina Denichenko, et al.

RNA 2014 20: 505-515 originally published online February 26, 2014

Access the most recent version at doi:10.1261/rna.042259.113

\section{Supplemental http://rnajournal.cshlp.org/content/suppl/2014/02/11/rna.042259.113.DC1 Material}

References This article cites 69 articles, 18 of which can be accessed free at: http://rnajournal.cshlp.org/content/20/4/505.full.html\#ref-list-1

Creative This article is distributed exclusively by the RNA Society for the first 12 months after the Commons License full-issue publication date (see http://rnajournal.cshlp.org/site/misc/terms.xhtml). After 12 months, it is available under a Creative Commons License (Attribution-NonCommercial 3.0 Unported), as described at http://creativecommons.org/licenses/by-nc/3.0/.
Email Alerting Receive free email alerts when new articles cite this article - sign up in the box at the Service top right corner of the article or click here.

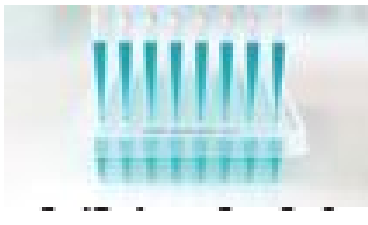

\section{Providing Precise Solutions for} your research.

To subscribe to $R N A$ go to:

http://rnajournal.cshlp.org/subscriptions 